\title{
An Overview to Soft-Switching Boost Converters for Photovoltaic
}

\author{
B. Abdi, Member, IACSIT, A. Safaei, J. S. Moghani, and H. Askarian Abyaneh
}

\begin{abstract}
In this paper, four different topologies of soft-switching boost converter using a simple auxiliary resonant circuit for solar power system are reviewed. These converters have simple structure, low cost and ease of control and are applicable for photovoltaic applications. Also, these topologies raise efficiency and, minimize switching losses by adopting soft-switching method using resonance. As we know efficiency, number of components and, voltage and current stresses are effective in selecting the converter for different applications. Therefore we need to choose the optimal boost converter considering above indexes. Efficiency, number of components and voltage and current stresses of these soft-switching boost converters have been compared in this paper to choose the optimal converter for photovoltaic application.
\end{abstract}

Index Terms - Soft-switching, boost converter, photovoltaic, comparison.

\section{INTRODUCTION}

Recently, Photovoltaic (PV) energy has attracted interest as a next generation energy source. It is capable of solving the problems of global warming and energy exhaustion caused by increasing energy consumption. The output voltage and power of the solar cell is easily changed by the surrounding conditions such as irradiation and temperature. So, a switching mode converter usually is used maximum power point tracking between solar cells and output inverter. Boost is the most simple and popular topology. Nonisolated DC-DC conversion applications like photovoltaic (PV) grid-connected power systems, electric vehicles (EV), fuel cells, uninterruptible power supplies (UPS), and high-intensity-discharge (HID) lamps for automobile headlamps call for high-performance step-up techniques [1, 2]. The common approach to these applications is a classical boost converter having simple structure, continuous input current, and clamped switch voltage stress to the output voltage.

Several kinds of soft-switching PWM converters, have been proposed in recent years trying to reduce switching losses, diode reverse recovery current, and the electromagnetic interference (EMI) noise of the pulse width modulation (PWM) controlled converters [3], [4]. Passive methods use only resonant inductors, capacitors, and diodes to achieve soft switching at turn-on and turn-off of the

Manuscript received October 9, 2012; revised November 25, 2012.

B. Abdi is with Damavand Branch, Islamic Azad University, Damavand, Tehran, Iran

A. Safaei, J. shokrollahi moghani, and H. Askarian Abyaneh are with the Amirkabir University of Technology, Department of Electrical Engineering, Tehran, Iran. (Corresponding author to provide e-mail: arman.safaee@ gmail.com). Address: No. 424, Hafez Ave, Electrical Engineering Department, Amirkabir University of Technology, 15914, Tehran. switches. Active methods use resonant inductors, capacitors, diodes, and auxiliary active switches to reduce switching loss due to main power switches. Recently, zero-voltage/current transition (ZVT/ZCT) PWM converters are proposed in addition to traditional zero voltage/current switching (ZVS/ZCS), which diminish voltage/current stresses of the main switch and achieve the soft switching of the main switch [5], [6].

However, the auxiliary circuit for resonance increases the complexity of the circuit, as well as its cost. For some resonant converters with an auxiliary switch, the main switch enables soft-switching, while the auxiliary switch performs hard switching. These converters cannot improve the whole system's efficiency owning to the switching losses of the auxiliary switch [7].

Since power converter are one of most important part of PV systems, an overview to four soft-switching boost converters are given here. This aim is very important for design and construction of PV power generators. All of selected converters have high efficiency, low cost, and ease of control. To selecting optimal soft-switching converter, it should be noted to the cost, complexity and reliability in addition to high efficiency. The brief operations of selected converters, which perfectly explain in [8]-[11], are given in section 2. Discussion about the converters is given in section 3 and section 4 is summery of the paper.

\section{OPERATION OF SELECTED SOFT-SwITCHING BOOST CONVERTERS}

\section{A. Case A}

Fig. 1, shows a soft-switching boost converter with an auxiliary switch and resonant circuit which is presented in [8]. The resonant circuit consist of a resonant inductor $\left(\mathrm{L}_{\mathrm{r}}\right)$, two resonant capacitors $\left(\mathrm{C}_{\mathrm{r}}\right.$ and $\left.\mathrm{C}_{\mathrm{r}}\right)$, two diodes $\left(\mathrm{D}_{1}\right.$ and $\left.\mathrm{D}_{2}\right)$, and an auxiliary switch $\left(\mathrm{S}_{2}\right)$. These resonant components make a partial resonant path for the main switch to perform soft switching under the zero-voltage condition using the resonant circuit. The operational principle of the proposed converter can be divided into nine modes. After turning on the auxiliary switch, the resonant inductor current begins to increase linearly and the main inductor current decreases. Immediately after the resonant inductor current and main inductor current have equalized, the main diode is turn off. Then the resonant capacitor $\left(\mathrm{C}_{\mathrm{r}}\right)$ and the resonant inductor start their resonance. After finishing the resonance, the resonant capacitor voltage is equal to zero, and the body diode of main switch is turn on naturally. The main switch turns on under zero-voltage condition and auxiliary switch is turned off. Then the resonant inductor and second resonant capacitor $\left(\mathrm{C}_{\mathrm{r} 2}\right)$ start their resonance. 
After the quarter-wave resonance of $\mathrm{L}_{\mathrm{r}}$ and $\mathrm{C}_{\mathrm{r} 2}, \mathrm{C}_{\mathrm{r} 2}$ has been fully charged, and the current flows the resonant inductor reverses. When the $\mathrm{C}_{\mathrm{r} 2}$ voltage has reached to zero by resonance, the body diode of the auxiliary switch is turned on. The main switch is turned off under the zero-voltage condition and the resonant capacitor $\mathrm{C}_{\mathrm{r}}$ has been charged by the sum of the two inductor currents to output voltage. Then, the main diode turns on under the zero-voltage condition and the resonant inductor current decreases linearly toward zero. Measured efficiency is about $96 \%$ in full load.

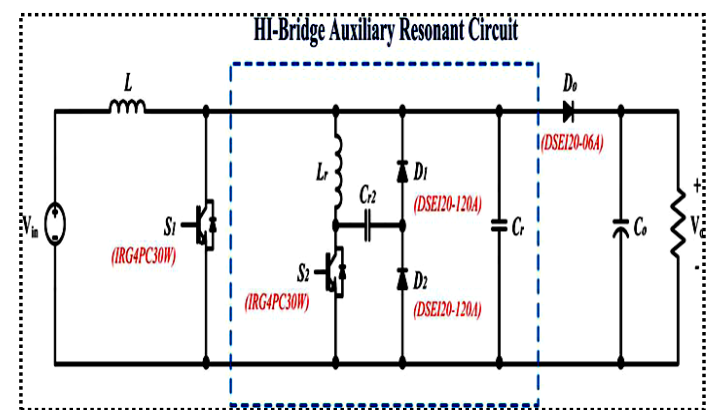

Fig. 1. Schematic of the soft- switching boost converter with an HI-bridge auxiliary resonant Circuit in [8]

\section{B. Case B}

Fig. 2, shows another soft-switching boost converter for photovoltaic power generation system [9]. One inductor $\left(\mathrm{L}_{2}\right)$, two capacitor $\left(\mathrm{C}_{\mathrm{r} 1}\right.$ and $\left.\mathrm{C}_{\mathrm{r} 2}\right)$ and two diodes $\left(\mathrm{D}_{1}\right.$ and $\left.\mathrm{D}_{2}\right)$ are added to the conventional boost converter circuit. On/Off control is done by one switch and the switching loss can be reduced by switching at zero-current and voltage made by $\mathrm{L}_{2}$ and $\mathrm{C}_{\mathrm{r} 2}$ resonance. This converter can be analyzed as seven modes according to the operation conditions.

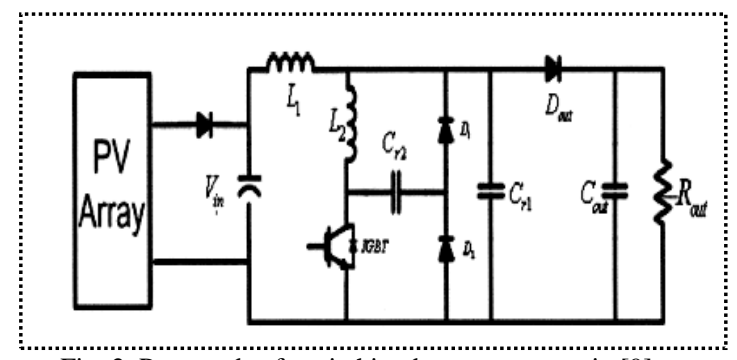

Fig. 2. Proposed soft switching boost converter in [9]

After turning on the switch under ZCS condition, the resonant inductor current increases linearly and main diode current decreases. If this current becomes the same as the current of the main inductor $\mathrm{L}_{1}$, the current of the output side diode becomes zero and turns off. Then the auxiliary resonant inductor $\mathrm{L}_{2}$ and the auxiliary capacitor $\mathrm{C}_{\mathrm{r} 1}$ resonate and the voltage of $C_{r 1}$ falls to zero and two auxiliary diodes $D_{1}$ and $D_{2}$ turn on naturally. After turning off the switch under zero-voltage condition, the voltage of the auxiliary resonant capacitor $\mathrm{C}_{\mathrm{r} 1}$ increases linearly from zero to the output voltage and the second resonance takes place. The energy stored at $\mathrm{L}_{2}$ moves to $\mathrm{C}_{\mathrm{r} 2}$. The current of $\mathrm{L}_{2}$ becomes zero and the voltage of $\mathrm{C}_{\mathrm{r} 2}$ becomes the maximum value.

After this period the voltage of $\mathrm{C}_{\mathrm{r} 2}$ decreases to zero and the current of $\mathrm{L}_{2}$ flows reversely and the anti-parallel diode of the switch turns on. The two currents of main inductor and auxiliary inductor transmit the energy to the output through main diode and decrease linearly. Finally the current of the auxiliary resonant inductor $\mathrm{L}_{2}$ becomes zero. The efficiency of this converter is about $96.85 \%$ at full load.

\section{Case C}

Third case of soft-switching boost converter is shown in Fig. 3, which provides ZCS turn-off of the main switch without additional conduction loss and current stress [10]. The auxiliary circuit consists of one switch $\left(\mathrm{S}_{\mathrm{a}}\right)$, one diode $\left(D_{\mathrm{a}}\right)$, one resonant inductor $\left(\mathrm{L}_{\mathrm{r}}\right)$ and one resonant capacitor $\left(\mathrm{C}_{\mathrm{r}}\right)$. It provides ZCS turn-off of all active switches and the resonant inductor, $\mathrm{L}_{\mathrm{r}}$ can minimize the reverse recovery problem of the main diode $\mathrm{D}_{\mathrm{f}}$, and also helps the soft turn-on of the main switch. This converter operates in eight modes. By turning on the main switch $\mathrm{S}$, the current through the resonant inductor $\mathrm{L}_{\mathrm{r}}$, and the main diode $\mathrm{D}_{\mathrm{f}}$, reduces linearly to zero and then the main diode $\mathrm{D}_{\mathrm{f}}$, is turned off softly. After this period the auxiliary switch is softly turned on under ZCS by resonant inductor, and then the resonance between the resonant inductor and the resonant capacitor starts. After the half of the resonant period, the resonant capacitor voltage reverses its polarity so the auxiliary diode starts conduction and the resonant inductor current flows oppositely.

The resonant inductor current is increased to negative sinusoidal value and the main switch current is reduced to zero and then the anti-parallel diode of the main switch starts conduction. The main switch and the auxiliary switch are turned off at the same time under ZCS to simplify the control design. The resonant capacitor voltage is charged to the output voltage by the input current and then the main diode turns on under ZVS condition and starts conduction. Finally the main switch is turned on again, and the switching cycle is repeated. This soft-switching boost converter is easy to control because the two switches are controlled by the same PWM signal. The measured efficiency of the proposed ZCT converter is measured about $95.2 \%$ at full load.

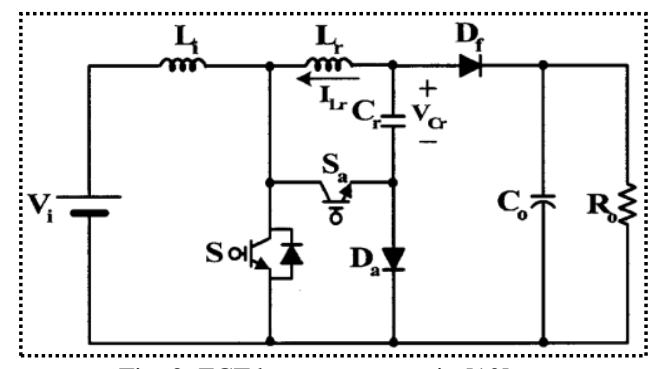

Fig. 3. ZCT boost converter in [10]

\section{Case D}

The circuit scheme of the last case is ZVT-PWM boost converter which is presented in [11] and shown in Fig. 4. The active snubber cell basically consists of an auxiliary resonant inductor $\left(\mathrm{L}_{\mathrm{r}}\right)$, a resonant capacitor $\left(\mathrm{C}_{\mathrm{B}}\right)$, an auxiliary transistor $\left(T_{2}\right)$, and two auxiliary diodes $\left(D_{1}\right.$ and $\left.D_{2}\right)$. In the proposed converter, the capacitor $\mathrm{Cr}$ in parallel with $\mathrm{T} 1$ is not required, and the diode $\mathrm{D}_{\mathrm{T} 1}$ in anti parallel with $\mathrm{T}_{1}$ may not be used. Seven stages occur in the steady state operation of the proposed converter over one switching cycle. When the auxiliary switch $T_{2}$ turns on, the resonant inductor current increases and the main diode current falls to zero and turned off under zero-voltage condition. Then a parallel resonance between $\mathrm{L}_{\mathrm{r}}$ and $\mathrm{C}_{\mathrm{r}}$ starts. After resonance period the voltage of $\mathrm{Cr}$ becomes zero and the anti parallel diode $\mathrm{D}_{\mathrm{T} 1}$ of the main switch is turned on. The main switch is turned on under 
TABLE I: COMPARISON OF PROPOSED BOOST CONVERTERS

\begin{tabular}{|c|c|c|c|c|c|c|c|c|c|c|c|}
\hline & & \multicolumn{4}{|c|}{ Number of auxiliary circuit component } & \multicolumn{6}{|c|}{ Voltage And Current Stresses } \\
\hline & \multirow[t]{2}{*}{$\begin{array}{l}\text { Eff. } \\
{[\%]}\end{array}$} & \multirow[t]{2}{*}{$\mathrm{Sw}$} & \multirow[t]{2}{*}{$\mathrm{D}$} & \multirow[t]{2}{*}{$\begin{array}{l}\text { Resonant } \\
\text { Inductor } \\
\text { uH/watt }\end{array}$} & \multirow[t]{2}{*}{$\begin{array}{l}\text { Resonant } \\
\text { Capacitor } \\
\text { nf/watt }\end{array}$} & \multicolumn{2}{|c|}{$\begin{array}{l}\text { Main switch } \\
{[\mathrm{V}],[\mathrm{A}]}\end{array}$} & \multicolumn{2}{|c|}{$\begin{array}{l}\text { Aux. Switch } \\
{[\mathrm{V}],[\mathrm{A}]}\end{array}$} & \multicolumn{2}{|c|}{$\begin{array}{l}\text { Main diode } \\
{[\mathrm{V}],[\mathrm{A}]}\end{array}$} \\
\hline & & & & & & $\mathrm{Vp}$ & Ip & $\mathrm{Vp}$ & Ip & $\mathrm{Vp}$ & Ip \\
\hline CASE A & 96 & 1 & 2 & $\mathrm{Lr}=33.3$ & $\begin{array}{l}\mathrm{Cr}=5.6 \\
\mathrm{Cr} 2=50\end{array}$ & 400 & 6 & 400 & 10 & 400 & 3.5 \\
\hline CASE B & 96.85 & - & 2 & $\mathrm{~L} 2=42.2$ & $\begin{array}{l}\mathrm{Cr} 1=83.3 \\
\mathrm{Cr} 2=8.3\end{array}$ & 650 & 12 & - & - & 400 & 12 \\
\hline CASE C & 95.2 & 1 & 1 & $\mathrm{Lr}=12.4$ & $\mathrm{Cr}=10$ & 338 & 7.6 & 341 & 9 & 665 & 7.7 \\
\hline CASE D & 97 & 1 & 2 & $\mathrm{Lr}=7.5$ & $\mathrm{CB}=11$ & 440 & 12 & 400 & 18 & 400 & 14 \\
\hline
\end{tabular}

zero-voltage condition and the auxiliary diode is turned off under near zero-voltage condition. Then $\mathrm{L}_{\mathrm{r}}$ and $\mathrm{C}_{\mathrm{r}}$ start their resonance. After resonance period the resonant inductor $\left(\mathrm{L}_{\mathrm{r}}\right)$ current decreases and the resonance capacitor $\left(\mathrm{C}_{\mathrm{B}}\right)$ is charged from zero to exactly the output voltage by $\mathrm{L}_{\mathrm{r}}$ current. As soon as resonant inductor current drops to zero, $D_{r}$ and $D_{1}$ are turned off under near zero-current condition. So, the main switch $T_{1}$ is turned off and the auxiliary diode $\mathrm{D}_{2}$ is turned on with ZVS by the capacitor $\left(C_{B}\right)$. During this stage when $C_{r}$ voltage reaches the output voltage $\mathrm{V}_{\mathrm{o}}$ and the auxiliary resonant capacitor $\left(\mathrm{C}_{\mathrm{B}}\right)$ voltage falls to zero simultaneously, the main diode $\mathrm{D}_{\mathrm{f}}$ is turned on with ZVS and the auxiliary diode $\mathrm{D}_{2}$ is turned off under zero-voltage condition. Finally the main diode continues conducting the input current and the snubber circuit is not active.

In this converter all of the semiconductor devices are both turned on and off under exact or near ZVS and/or ZCS. The converter has a simple structure, low cost, ease of control and high efficiency. At full output power in the proposed soft-switching boost converter, the main switch loss is about $27 \%$ and the total circuit loss is about $36 \%$ of that in its counterpart hard switching converter, and so the overall efficiency, which is about $91 \%$ in the hard switching case, increases to about $97 \%$ [11].

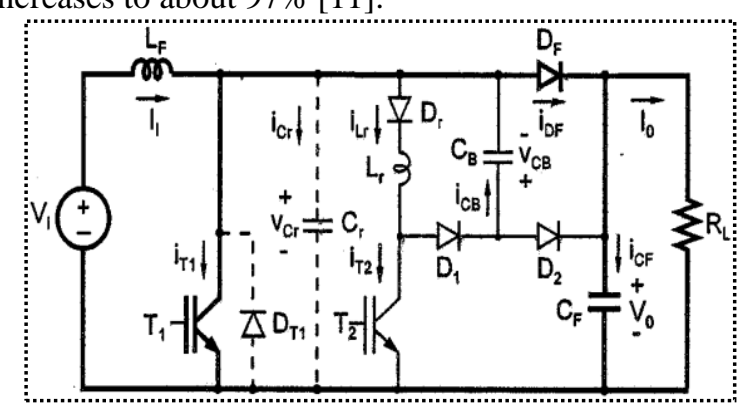

Fig. 4. Circuit scheme of the ZVT boost converter in [11]

\section{DISCUSSION AND COMPARISON}

Efficiency (Eff.), number of auxiliary switch (sw), diode (D), resunant inductor (L) and capacitor (C) beside their amount and voltage and current stresses of main switch, auxiliary switch and main diode of these four soft-switching boost converters system have been summarized in TABLE .

TABLE, shows the efficiency of each converter. We can see that the converter in CASE $\mathrm{C}$ has the minimum efficiency and the converter in CASE D has the maximum efficiency. So, the converter in CASE D is more appropriate for PV application from this aspect.

TABLE, also shows the number of auxiliary components that have been used in auxiliary resonant circuit of each soft-switching boost converter. The number of devises and the value of resonant capacitor and resonant inductor are effective on the cost of the converter. However the number of components is more, the converter will be more expensive.

We can see that the boost converter in CASE $C$ has the minimum auxiliary components and the converters in CASE $\mathrm{A}, \mathrm{D}$ have the maximum auxiliary components. Therefore the converter in CASE C will be more economically.

The current/voltage stresses of main switch, auxiliary switch, and main diode of the proposed converters have been shown in TABLE. The converter in CASE $B$ has the maximum voltage and current stresses on main switch. The converter in CASE D has the maximum current stress on auxiliary switch whiles the converter in CASE C has the minimum current stress on auxiliary switch. Finally we can see that the converter in CASE $\mathrm{C}$ has the maximum voltage stress on main diode and the converter in CASE B has maximum current stress on main diode.

\section{CONCLUSION}

In this paper four different kind of soft switching boost converters with auxiliary resonant circuit for photovoltaic applications have been reviewed. Through this auxiliary resonant circuit, all of the switching devices perform soft-switching under zero-voltage and zero-current conditions. These boost converters have high efficiency, low cost, and ease of control. The efficiency of these boost converters is more than $95 \%$ and are useful for photovoltaic application. The operation principle of these converters was expressed briefly. As we know in addition to efficiency, number of auxiliary components and current /voltage stresses are effective in selecting the optimal converter for 
photovoltaic applications. Therefore we must look to these factors. So, efficiency, number of auxiliary components and current/voltage stresses of these converters have been compared in this paper.

\section{REFERENCES}

[1] F. Blaabjerg, Z. Chen, and S. B. Kjaer, "Power electronics as efficient interface in dispersed power generation systems," IEEE Trans. Power Electron., vol. 19, no. 5, pp. 1184-1194, Sep. 2004.

[2] R. J.Wai and V. H. Wang, "Grid-connected photovoltaic generation system," IEEE Trans. Circuit And System, vol. 55, no. 3, pp. 953-963, Apr. 2008.

[3] G. Hua and F. C. Lee, "Soft-switching techniques in PWM converters," IEEE Trans. Industrial Electronics, vol. 42, no. 6, pp. 595-603, Dec. 1994.

[4] G. Hua, E. X. Yang, Y. Jiang, and F. C. Lee, "Novel zero-current-transition PWM converters," IEEE Trans. Power Electron, vol. 9, pp. 601-606, Nov. 1994. IEEE Trans. Ind. Applications, vol. 33, pp. 1220-1232, Sept./Oct. 1997.

[5] Y. Zhang and P. C. Sen, "A new soft-switching technique for Buck, Boost, and Buck-Boost converters," IEEE Trans. Industry Applications, vol. 39, no. 6, pp. 1775-1782, Nov 2003.

[6] H. Bodur and A. F. Bakan, "A new ZVT-ZCT-PWM DC-DC converter," IEEE Trans. Power Electron, vol. 19, no. 3, pp. 676-684, May 2004.

[7] H. Bodur and A. F. Bakan, "A new ZVT-ZCT-PWM DC-DC converter," IEEE Trans. Power Electron, vol. 25, no. 8, pp. 2093-2105, Aug. 2010.

[8] S. H. Park, S. R. Park, J. S. Yu, Y. C. Jung, and C. Y. Won, "Analysis and Design of a Soft-Switching Boost Converter with an HI-Bridge Auxiliary Resonant Circuit," IEEE Trans. Power. Electronics, vol. 25, no. 8, pp. 2142-2149, Aug. 2010.

[9] D. Y. Jung and C. Y. Won, "Soft Switching Boost Converter for Photovoltaic Power Generation System," International Power Electronics and motion control Conference, pp.1929-1933, 2008.

[10] D. Y. Lee, M. K. Lee, D. S. Hyun, and I. Choy, "New zero-current-transition PWM DC/DC converters without current stress," IEEE Trans. Power Electronics, vol. 18, no. 1, pp. 95-104, Jan 2003.

[11] H. Bodur and A. F. Bakan, "A new ZVT-PWM DC-DC converter," IEEE Trans. Power Electronics, vol. 17, no. 1, pp. 40-47, Jan 2002.

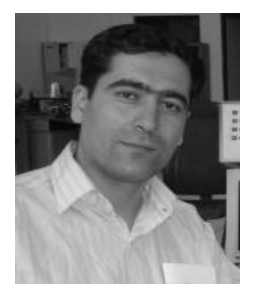

Babak Abdi was born in Tehran, in 1976. He received his MS and $\mathrm{PhD}$ degree in electrical engineering in 2005 and 2009 from Amirkabir University of Technology (Tehran Polytechnic), Tehran, Iran, respectively. He is currently a member of IEEE and faculty member of Islamic Azad UniversityDamavand branch, Tehran, Iran. His research interests include power electronics, application of reliability in power electronics, Electromagnetic Interferences
(EMI), electrical machines and drives.

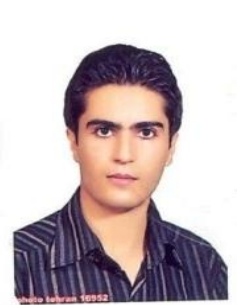

Arman Safaei was born in Qazvin, on June 23, 1988. He received the B.S. degree from Zanjan University, Zanjan, Iran in 2006. Currently, he is the M.S student in Electrical Engineering at Amirkabir University of Technology, Tehran, Iran. His research interests include power system protection, impact of DGs on power system, optimization methods, and renewable energy.

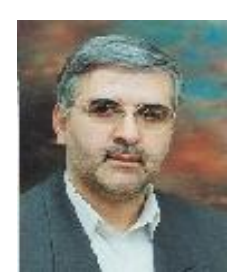

Javad Shokrollahi Moghani was born in Tabriz, Iran in 1956. He received the B.Sc. and M.Sc. degrees in electrical engineering from the South Bank Polytechnic and Lough borough University of Technology, England, in 1982 and 1984 respectively. Since 1984 until 1991 he was with the Department of Electrical Engineering, Amirkabir University of Technology, Tehran, Iran. He received his $\mathrm{PhD}$ degree in electrical engineering from Bath University, Bath, England in 1995 and is back to Amirkabir University of Technology since. His research interests include Electromagnetic System Modeling and Design using FEM, DC-DC converters and Electric Drives.

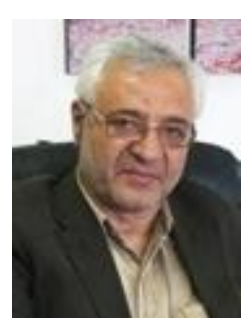

H. Askarian Abyaneh (SM'09) was born in Abyaneh Isfahan, on March 20, 1953. He received the B.S. degree from Iran University of Science and Technology in 1976 and the M.S. degree from Tehran University, Tehran, Iran, in 1982. He received a second M.S. degree and Ph.D. degree in electrical power system engineering from the University of Manchester Institute of Science and Technology, Manchester, U.K., in 1985 and 1988, respectively. Currently, he is a Professor with the Department of Electrical Engineering, Amirkabir University of Technology, Tehran, Iran, working in the area of the relay protection and power quality. He has been published in many scientific papers in international journals and conferences. 